\title{
Type of milk feeding in infancy and health behaviours in adult life: findings from the Hertfordshire Cohort Study
}

\author{
Siân Robinson*, Georgia Ntani, Shirley Simmonds, Holly Syddall, Elaine Dennison, Avan Aihie Sayer, \\ David Barker, Cyrus Cooper and the Hertfordshire Cohort Study Group \\ MRC Lifecourse Epidemiology Unit, University of Southampton, Southampton General Hospital, Southampton SO16 6YD, UK
}

(Submitted 20 June 2011 - Final revision received 15 February 2012 - Accepted 19 February 2012 - First published online 5 July 2012)

\begin{abstract}
A number of studies suggest that breast-feeding has beneficial effects on an individual's cardiovascular risk factors in adulthood, although the mechanisms involved are unknown. One possible explanation is that adults who were breastfed differ in their health behaviours. In a historical cohort, adult health behaviours were examined in relation to type of milk feeding in infancy. From 1931 to 1939 , records were kept on all infants born in Hertfordshire, UK. Their type of milk feeding was summarised as breastfed only, breast and bottle-fed, or bottlefed only. Information about adult health behaviours was collected from 3217 of these men and women when they were aged 59-73 years. Diet was assessed using an administered FFQ; the key dietary pattern was a 'prudent' pattern that described compliance with 'healthy' eating recommendations. Of the study population, $60 \%$ of the men and women were breastfed, $31 \%$ were breast and bottle-fed, and $9 \%$ were bottle-fed. Type of milk feeding did not differ according to social class at birth, and was not related to social class attained in adult life. There were no differences in smoking status, alcohol intake or reported physical activity according to type of milk feeding, but there were differences in the participants' dietary patterns. In a multivariate model that included sex and infant weight gain, there were independent associations between type of feeding and prudent diet scores in adult life $(P=0 \cdot 009)$, such that higher scores were associated with having been breastfed. These data support experimental findings which suggest that early dietary exposures can have lifelong influences on food choice.
\end{abstract}

Key words: Breast-feeding: Food choice: Dietary patterns: Health behaviours

There is now a substantial body of evidence that environmental influences acting in early development are linked to later health ${ }^{(1)}$. In the early postnatal period, there is particular interest in the extent to which variations in infant nutrition affect growth, development and later function. Analyses of longitudinal cohorts have shown that the type of milk feeding in infancy may be important, as breast-feeding is associated with small reductions in blood pressure ${ }^{(2)}$ and serum cholesterol in adult life ${ }^{(3,4)}$, and with a lower risk of becoming overweight $^{(5,6)}$ and developing type 2 diabetes $^{(7)}$.

The mechanisms that underlie the links between type of milk feeding and later health are not understood. In terms of risk of later obesity, it is possible that because breastfed babies control the amount of milk they consume, they learn effective self-regulation of energy intake in early life ${ }^{(8,9)}$. Another explanation may be that the bioactive components in breast milk have long-term 'programmed' effects on function. For example, early exposure to leptin and adiponectin in breast milk could be involved in setting endocrine responses to feeding ${ }^{(10)}$. However, a third possibility is that there are behavioural differences between adults who were breastfed or formula-fed in infancy. There is some evidence that breast-feeding affects the acquisition of taste preferences in infancy, which may be important in establishing lifelong food habits ${ }^{(11,12)}$. Alternatively, early exposure to breast milk may be associated with a more beneficial profile of health behaviours in later life, which includes having a healthier diet. The finding, from follow-up of a historical cohort, that breast-feeding was associated with higher educational attainment and with greater upward social mobility is consistent with this possibility ${ }^{(13)}$, as such effects would be expected to make an impact on responses to health messages in adult life, and consequent health behaviours. However, in developed populations, it is difficult to assess the effects of breast-feeding on later diet, as the choice to breastfeed is often associated with higher maternal social class and educational attainment - both characteristics that are also likely to influence children's dietary patterns ${ }^{(14)}$.

Using data from a cohort of 3217 adults who were born in the 1930s, at a time when breast-feeding in the UK was more

Abbreviation: HCS, Hertfordshire Cohort Study.

*Corresponding author: S. Robinson, fax +44238070 4021, email smr@mrc.soton.ac.uk 
common $^{(15)}$, and social gradients in feeding practice were much less marked than today ${ }^{(16)}$, health behaviours, including compliance with 'healthy' eating recommendations, level of physical activity, smoking behaviour and alcohol consumption in adult life were examined according to type of milk feeding in infancy. The aim of the present study was to test the hypothesis that breast-feeding is associated with a beneficial profile of health behaviours in later life.

\section{Subjects and methods}

\section{The Hertfordshire Cohort Study}

From 1911 to 1948, health visitors kept detailed records on all infants born in the county of Hertfordshire, UK. These records have been described previously ${ }^{(17)}$. In 1998, 7106 men and women who were born between 1931 and 1939 and who were still living in Hertfordshire were traced using the National Health Service (NHS) central register. General practitioners gave permission for us to write to 3126 (82\%) men and 2973 (91\%) women. Of these, 1684 (54\%) men and 1541 (52\%) women agreed to be interviewed at home by a trained research nurse when diet was assessed and information was obtained on the participant's medical and social history.

This study was conducted according to the guidelines laid down in the Declaration of Helsinki and all procedures were approved by the Bedfordshire and Hertfordshire Local Research Ethics Committee and the West Hertfordshire Local Research Ethics Committee. All participants gave written informed consent.

\section{Early-life data}

Infants were visited throughout their first year by a health visitor (median number of visits 12 (interquartile range 11-13)). Details of infant feeding and weights obtained at these visits were documented on record cards. At the end of the year, the information for each infant was summarised in a ledger. The type of milk feeding in infancy was categorised as 'breastfed only', 'breast and bottle-fed', or 'bottle-fed only', and weights at birth and at 1 year of age were recorded. The record cards containing more detailed information on type of feeding, feeding duration and infant's weight (determined at individual visits) were not retained.

\section{Dietary assessment}

Diet was assessed using a FFQ that included 129 foods and food groups, and was based on the European Prospective Investigation into Cancer and Nutrition questionnaire ${ }^{(18)}$. An average frequency of consumption of the listed foods over the 3-month period preceding the home interview was recorded. Each FFQ was administered by a trained research nurse, and prompt cards were used to show the foods included in each food group, to ensure standardised responses to the FFQ. Frequencies of other foods that were not listed on the FFQ were also recorded if consumed once per week or more. Complete dietary data were available for 1677 (54\%) men and 1540 (52\%) women.

The foods listed in the FFQ were classified into fifty-one food groups on the basis of similarity of type of food and nutrient composition. For example, carrots, parsnips, swede and turnip were included in the 'root vegetables' group; bacon, ham, corned beef, pies and sausages were included in the 'processed meats' group. Any foods listed at the end of the FFQ (e.g. stanol-containing fat spreads, pheasant) were allocated to one of the fifty-one groups according to their use and composition. Principal components analysis (PCA) of the reported weekly frequencies of consumption of these food groups was used to define patterns of diet. The first component, that explained the most variance in the dietary data (8\%), described a pattern of foods that was characterised by high consumption of fruit, vegetables, wholemeal cereals and oily fish but by low consumption of white bread and chips, sugar and full-fat dairy products. This pattern of diet reflects UK recommendations for a healthy diet and was called a 'prudent' diet in common with other published studies $^{(19,20)}$. A prudent diet score was calculated for each participant using the coefficients for each food group defined by the PCA, multiplied by their reported frequency of consumption of the group, and these values were summed. The score indicates their compliance with the pattern. A high prudent diet score (in the upper part of distribution of scores) indicates a diet characterised by high consumption of fruit, vegetables, wholemeal cereals and oily fish; while a low score (in the lower part of the distribution of scores) indicates a diet characterised by high consumption of white bread and chips, sugar and full-fat dairy products. Nutrient supplements were not included in the PCA. A second 'traditional' dietary pattern has also been described in this cohort ${ }^{(18)}$, but the present analyses only considered the prudent dietary pattern, as an indicator of the participants' understanding and adherence to healthy eating guidance.

\section{Data analysis}

Social class at birth was coded according to father's occupation $^{(21)}$ and categorised in two groups (non-manual occupations: I (professional), II (managerial and technical), IIINM (skilled non-manual); manual occupations: IIIM (skilled manual), IV (partly skilled), V (unskilled)). Birth order and age at leaving full-time education were reported by the participant at interview. Information on the type of milk feeding, birth weight and weight at 1 year for the Hertfordshire Cohort Study (HCS) participants was abstracted from the original ledgers. Weight gain in the first year was characterised by calculating sex-specific standard deviation scores that were conditional on birth weight ${ }^{(22)}$. This measure is free of artefactual effects of regression to the mean, and is a standardised measure of an individual's growth in the first year of life in comparison with that expected for their birth weight. Adult lifestyle characteristics were reported at interview. Current smoking status was categorised in three groups (smokers, ex-smokers and non-smokers). Units of alcohol consumed each week were calculated from the reported frequency 
(seven frequency categories ranging from never to more than once per day) and amount consumed of five different types of alcoholic drinks. One unit of alcohol was equivalent to $284 \mathrm{ml}$ beer, $125 \mathrm{ml}$ wine, $50 \mathrm{ml}$ fortified wine or $25 \mathrm{ml}$ spirits ${ }^{(23)}$. A standardised activity score, ranging from 0 to 100 , was calculated based on responses to questions about the frequency of gardening, housework, climbing stairs and carrying loads in a typical week. Higher scores indicate a greater level of activity $^{(23)}$. Current social class was coded according to current or most recent occupation for men and never-married women, or from husband's occupation for ever-married women, and categorised in two groups ${ }^{(21)}$.

Trends in outcome measures were considered across the three milk-feeding groups (breast, breast and bottle, bottle). Bottle foods available in the 1930s included patent preparations of dried cows' milk, unmodified cows' milk and diluted condensed milk $^{(24)}$. The trends across the three groups were taken to indicate graded changes in exposure to breast milk in the first year of life. Normality of variables was assessed and variables transformed as required. Differences in the continuous variables between men and women were tested using $t$ tests and Wilcoxon rank-sum tests where appropriate, while differences in proportions were tested by Pearson's $\chi^{2}$ test. To investigate the associations between early-life characteristics and type of infant feeding, ordered logistic regression was performed. The assumption of proportionality of odds across the milk-feeding groups was tested for all fitted models. Univariate and multiple regression analyses were used to investigate associations between infant milk feeding and outcomes in adult life, with and without adjustment for significant early-life effects (birth weight, weight gain) and other adult lifestyle characteristics. Spearman rank correlation was used to test for trend in the consumption of individual foods across milk-feeding groups and across categories of infant weight gain. Data were analysed using Stata version 11 (Stata Corporation) $^{(25)}$.

\section{Results}

The men and women studied were aged between 59 and 73 years of age: men 65.6 (SD 2.9), women 66.6 (SD 2.7) years. Their characteristics are shown in Table 1 . With the exception of weight at birth, there were no differences between the men and women in their early-life characteristics, including their type of milk feeding. In adult life, the men and women were of similar social class, but differed in their health behaviours such that men were more likely to smoke, to have a higher alcohol consumption and to have a poorer diet, with a lower prudent diet score. In contrast, their activity scores tended to be higher than those of the women studied.

The early-life characteristics of the men and women are shown according to the type of milk feeding in infancy in Table 2. The type of milk feeding did not differ by social class at birth or by birth order. However, there were associations with size at birth and with conditional weight gain in the first year. Breast-feeding was more common among babies of higher birth weight, although the differences in weight were small, and was associated with lower weight gain in the first year. Weight at birth and infant weight gain were not related $(P=0.683)$, and remained independently associated with the type of milk feeding in a multivariate model (both $P<0 \cdot 001$, data not shown). Age at leaving fulltime education was not related to the type of milk feeding in infancy.

The adult lifestyle characteristics of the men and women are shown according to the type of milk feeding in infancy in Table 3. Social class attained in adult life was not related to the type of milk feeding. Of the health behaviours considered, only adult diet differed between the feeding groups, with higher prudent diet scores found among the men and women who had been breastfed only, and lower scores in those who had been bottle-fed only. Since all the health behaviours differed between the men and women (Table 1), multivariate models were used to examine their associations with the type of milk feeding after taking account of the effect of sex. Inclusion of sex made little difference to the associations between type of milk feeding and smoking, alcohol consumption and activity score (data not shown), but the relationship between the type of milk feeding and adult prudent diet score remained $(P=0 \cdot 031)$.

As birth weight and conditional weight gain in the first year were related to the type of milk feeding (Table 2), their independent associations with adult prudent diet scores were examined in a multivariate model (Table 4). Prudent diet scores were independently related to the type of milk feeding and to weight gain in infancy, but there was no independent association with weight at birth. Their separate associations are illustrated in Fig. 1. At each level of infant weight gain, higher prudent diet scores were found among the men and women who had been breastfed only. Likewise, within each feeding group, greater conditional weight gain was associated with higher prudent diet scores in adult life. There was no interaction between type of milk feeding and conditional weight gain in their relationships with prudent diet score $(P=0.806)$. In previous analyses of this cohort, higher prudent diet scores have been described in men and women of higher social class, in non-smokers and in those who left full-time education at an older age ${ }^{(16)}$. After including these correlates of the prudent dietary pattern in the model, the independent associations between type of milk feeding in infancy and infant weight gain with prudent diet score remained ( $P=0.045$ type of milk feeding; $P<0.001$ weight gain in first year).

High prudent diet scores are indicative of diets that are characterised by differences in consumption of a range of foods that includes higher intakes of fruit, vegetables, oily fish and wholemeal cereals but lower intakes of white bread, added sugar, full-fat dairy products, chips and processed meat. Type of milk feeding in infancy and infant weight gain were therefore examined in relation to the consumption of individual foods. With the exception of full-fat dairy products, consumption of the foods that characterised the prudent pattern were associated with either infant feeding type or weight gain in infancy, or both. Consumption of the key foods ${ }^{(18)}$ is shown in Tables 5 and 6. There was no evidence of particular associations between infant feeding 
Table 1. Early-life and adult characteristics of the men and women studied

(Number of subjects and percentages; mean values and standard deviations; median values and interquartile ranges (IQR))

\begin{tabular}{|c|c|c|c|c|c|c|c|}
\hline & \multicolumn{2}{|c|}{ All } & \multicolumn{2}{|c|}{ Men } & \multicolumn{2}{|c|}{ Women } & \multirow[b]{2}{*}{$P^{*}$} \\
\hline & $n$ & $\%$ & $n$ & $\%$ & $n$ & $\%$ & \\
\hline$n$ & \multicolumn{2}{|c|}{3217} & \multicolumn{2}{|c|}{1677} & \multicolumn{2}{|c|}{1540} & \\
\hline \multicolumn{8}{|l|}{ Early life } \\
\hline \multicolumn{8}{|l|}{ Social class at birth $\dagger$} \\
\hline I, II and IIINM & 485 & $16 \cdot 1$ & 247 & $15 \cdot 7$ & 238 & 16.5 & 0.534 \\
\hline IIIM, IV and V & 2531 & 83.9 & 1328 & $84 \cdot 3$ & 1203 & 83.5 & \\
\hline \multicolumn{8}{|l|}{ Birth ordert } \\
\hline First & 1245 & 38.8 & 646 & $38 \cdot 6$ & 599 & $39 \cdot 0$ & 0.723 \\
\hline Second & 876 & $27 \cdot 3$ & 467 & $27 \cdot 9$ & 409 & $26 \cdot 6$ & \\
\hline Third & 452 & 14.1 & 239 & $14 \cdot 3$ & 213 & 13.9 & \\
\hline Fourth or more & 640 & $19 \cdot 9$ & 323 & $19 \cdot 3$ & 317 & $20 \cdot 6$ & \\
\hline Birth weight $(\mathrm{kg})$ & & & & & & & $<0.001$ \\
\hline Mean & \multicolumn{2}{|c|}{3.43} & \multicolumn{2}{|c|}{3.50} & \multicolumn{2}{|c|}{3.35} & \\
\hline SD & \multicolumn{2}{|c|}{0.53} & \multicolumn{2}{|c|}{0.54} & \multicolumn{2}{|c|}{0.50} & \\
\hline Weight gain in first year (SD) & & & & & & & 0.922 \\
\hline Mean & \multicolumn{2}{|c|}{0.06} & \multicolumn{2}{|c|}{0.06} & \multicolumn{2}{|c|}{0.06} & \\
\hline SD & \multicolumn{2}{|c|}{0.99} & \multicolumn{2}{|c|}{0.98} & \multicolumn{2}{|c|}{1.00} & \\
\hline \multicolumn{8}{|l|}{ Type of milk feeding in infancy } \\
\hline Breast only & 1937 & $60 \cdot 2$ & 1008 & $60 \cdot 1$ & 929 & $60 \cdot 3$ & 0.947 \\
\hline Breast + bottle & 984 & $30 \cdot 6$ & 512 & 30.5 & 472 & $30 \cdot 7$ & \\
\hline Bottle only & 296 & $9 \cdot 2$ & 157 & $9 \cdot 4$ & 139 & $9 \cdot 0$ & \\
\hline \multicolumn{8}{|c|}{ Age at leaving full-time education $\dagger$} \\
\hline Up to 14 years & 601 & $18 \cdot 7$ & 325 & $19 \cdot 4$ & 276 & 17.9 & 0.286 \\
\hline 15 years or older & 2615 & $81 \cdot 3$ & 1351 & $80 \cdot 6$ & 1264 & $82 \cdot 1$ & \\
\hline Adult life & & & & & & & \\
\hline Social class in adult life $†$ & & & & & & & \\
\hline Non-manual & 1303 & $41 \cdot 2$ & 664 & $40 \cdot 8$ & 639 & 41.5 & 0.685 \\
\hline Manual & 1863 & 58.8 & 963 & $59 \cdot 2$ & 900 & 58.5 & \\
\hline Smoking status $\dagger$ & & & & & & & \\
\hline Never & 1468 & $45 \cdot 7$ & 545 & $32 \cdot 5$ & 923 & $60 \cdot 0$ & $<0.001$ \\
\hline Ex-smoker & 1319 & 41.0 & 870 & 51.9 & 449 & $29 \cdot 2$ & \\
\hline Current & 428 & 13.3 & 262 & $15 \cdot 6$ & 166 & $10 \cdot 8$ & \\
\hline Alcohol intake (units/week) & & & & & & & $<0.001$ \\
\hline Median & & & & & & & \\
\hline IQR & & & & & & & \\
\hline Prudent diet score (SD) & & & & & & & $<0.001$ \\
\hline Mean & & & & & & & \\
\hline SD & & & & & & & \\
\hline Activity score & & & & & & & $<0.001$ \\
\hline Mean & & & & & & & \\
\hline SD & & & & & & & \\
\hline
\end{tabular}

I, professional; II, managerial and technical; IIINM, skilled non-manual; IIIM, skilled manual; IV, partly stilled; V, unskilled.

${ }^{*} P$ for difference between men and women using $t$ test (birth weight, weight gain, prudent diet and activity scores), Wilcoxon rank-sum test (alcohol intake) and Pearson's $\chi^{2}$ test (social class, birth order, type of milk feeding, age at leaving education, smoking status).

† Includes some missing values.

and infant growth with the consumption of any individual foods that characterised the pattern, or with any of the remaining foods in the adult diet (data not shown). Where there were significant trends in the consumption of individual foods, these appeared to be due both to differences in proportions of consumers across the feeding and weight gain groups, and to differences in the frequency of consumption among the consumers. For example, the proportion of men and women who added sugar to their food ranged from $44 \%$ of the breastfed group to $50 \%$ of the bottle-fed group; the equivalent proportions of consumers with high added sugar consumption ( $>4$ teaspoons/d) were 54 and $62 \%$. The pattern was similar according to weight gain in infancy. For example, $87 \%$ of men and women in the bottom-third of the distribution (Table 6) ate any oily fish, compared with $90 \%$ of those in the top-third. The proportion of oily fish consumers with high intakes ( $>1$ /week) was 53 and $61 \%$ in the bottom and top weight gain groups, respectively.

Since an independent association was found between infant weight gain and prudent diet score in adult life, in the final analyses its associations with the other health behaviours were examined. In multivariate models (that also included sex, birth weight and type of milk feeding), there were no associations between infant weight gain and smoking status $(P=0.98)$, alcohol consumption $(P=0.34)$ or activity score $(P=0.95)$.

\section{Discussion}

The present study found that the diets of older men and women who had been breastfed differed from those who had been bottle-fed, such that greater exposure to breast 
Table 2. Early-life characteristics of the men and women studied, according to type of milk feeding in infancy (Number of subjects and percentages; mean values and standard deviations)

\begin{tabular}{|c|c|c|c|c|c|c|c|}
\hline & \multicolumn{2}{|c|}{ Breast only } & \multicolumn{2}{|c|}{ Breast + bottle } & \multicolumn{2}{|c|}{ Bottle only } & \multirow[b]{2}{*}{$P^{*}$} \\
\hline & $n$ & $\%$ & $n$ & $\%$ & $n$ & $\%$ & \\
\hline$n$ & \multicolumn{2}{|c|}{1937} & \multicolumn{2}{|c|}{984} & \multicolumn{2}{|c|}{296} & \\
\hline \multicolumn{8}{|l|}{ Social class at birth } \\
\hline Non-manual & 302 & $16 \cdot 4$ & 140 & $15 \cdot 4$ & 43 & $15 \cdot 9$ & 0.526 \\
\hline Manual & 1534 & 83.6 & 769 & $84 \cdot 6$ & 228 & $84 \cdot 1$ & \\
\hline \multicolumn{8}{|l|}{ Birth order } \\
\hline First & 729 & $37 \cdot 7$ & 389 & $39 \cdot 6$ & 127 & $42 \cdot 9$ & 0.079 \\
\hline Second & 528 & $27 \cdot 3$ & 265 & $27 \cdot 0$ & 83 & 28.0 & \\
\hline Third & 284 & 14.7 & 134 & $13 \cdot 6$ & 34 & 11.5 & \\
\hline Fourth or more & 393 & $20 \cdot 3$ & 195 & $19 \cdot 8$ & 52 & $17 \cdot 6$ & \\
\hline Birth weight (kg) & & & & & & & $<0.001$ \\
\hline Mean & \multicolumn{2}{|c|}{3.46} & \multicolumn{2}{|c|}{$3 \cdot 42$} & \multicolumn{2}{|c|}{$3 \cdot 31$} & \\
\hline SD & \multicolumn{2}{|c|}{0.52} & \multicolumn{2}{|c|}{0.51} & \multicolumn{2}{|c|}{0.61} & \\
\hline Weight gain in first year (SD) & & & & & & & $<0.001$ \\
\hline Mean & \multicolumn{2}{|c|}{0.00} & \multicolumn{2}{|c|}{0.13} & \multicolumn{2}{|c|}{0.20} & \\
\hline SD & \multicolumn{2}{|c|}{0.96} & \multicolumn{2}{|c|}{1.00} & \multicolumn{2}{|c|}{1.08} & \\
\hline Age at leaving full-time education & & & & & & & 0.559 \\
\hline Up to 14 years & 361 & $18 \cdot 6$ & 94 & $19 \cdot 7$ & 46 & $15 \cdot 5$ & \\
\hline 15 years or older & 1575 & 81.4 & 790 & $80 \cdot 3$ & 250 & 84.5 & \\
\hline
\end{tabular}

${ }^{*} P$ for trend across the milk-feeding groups using ordered logistic regression.

milk was associated with diets that were characterised by greater consumption of fruit, vegetables, wholemeal cereals and oily fish, and low consumption of refined cereals, sugar and full-fat dairy products. This association, while modest in terms of effect size, was robust to adjustment for confounding factors that included adult correlates of the dietary pattern, such as smoking and social class ${ }^{(18)}$. The lack of associations between type of milk feeding and other health behaviours suggests that the differences in adult diet are not simply a response to general recommendations for a healthy lifestyle, but that there may be specific effects of infant dietary exposures on food choices made in adult life. Additionally, independent of type of feeding, greater weight gain in the first year was related to differences in later diet; greater infant weight gain was associated with healthier dietary choices in adult life. To our knowledge, such differences in adult diet in relation to type of milk feeding and growth in infancy have not been described before.

There may be different mechanisms that link infant diet and growth to adult diet. In terms of infant diet, it is possible that differences in early exposures affect the acquisition of taste preferences, which influence later food choice. This would

Table 3. Adult social class and health behaviours of the men and women studied, according to type of milk feeding in infancy

(Number of subjects and percentages; mean values and standard deviations; median values and interquartile ranges (IQR))

\begin{tabular}{|c|c|c|c|c|c|c|c|}
\hline & \multicolumn{2}{|c|}{ Breast only } & \multicolumn{2}{|c|}{ Breast + bottle } & \multicolumn{2}{|c|}{ Bottle only } & \multirow[b]{2}{*}{$P^{*}$} \\
\hline & $n$ & $\%$ & $n$ & $\%$ & $n$ & $\%$ & \\
\hline$n$ & \multicolumn{2}{|c|}{1937} & \multicolumn{2}{|c|}{984} & \multicolumn{2}{|c|}{296} & \\
\hline \multicolumn{8}{|l|}{ Social class in adult life } \\
\hline Non-manual & 817 & 42.9 & 364 & 37.5 & 122 & $42 \cdot 1$ & 0.096 \\
\hline Manual & 1088 & $57 \cdot 1$ & 607 & 62.5 & 168 & 57.9 & \\
\hline \multicolumn{8}{|l|}{ Smoking status } \\
\hline Never & 899 & $46 \cdot 4$ & 436 & $44 \cdot 3$ & 133 & 44.9 & 0.211 \\
\hline Ex-smoker & 793 & $41 \cdot 0$ & 405 & $41 \cdot 2$ & 121 & $40 \cdot 9$ & \\
\hline Current & 243 & $12 \cdot 6$ & 143 & $14 . \overline{5}$ & 42 & $14 \cdot 2$ & \\
\hline Alcohol intake (units/week) & & & & & & & 0.235 \\
\hline Median & \multicolumn{2}{|c|}{5.5} & \multicolumn{2}{|c|}{$5 \cdot 0$} & \multicolumn{2}{|c|}{4.9} & \\
\hline IQR & \multicolumn{2}{|c|}{$1.5-14.0$} & \multicolumn{2}{|c|}{$1.5-14.0$} & \multicolumn{2}{|c|}{$1 \cdot 0-13 \cdot 4$} & \\
\hline Prudent diet score (SD) & & & & & & & 0.034 \\
\hline Mean & \multicolumn{2}{|c|}{0.06} & \multicolumn{2}{|c|}{-0.08} & \multicolumn{2}{|c|}{-0.14} & \\
\hline SD & \multicolumn{2}{|c|}{1.97} & \multicolumn{2}{|c|}{$2 \cdot 13$} & \multicolumn{2}{|c|}{1.98} & \\
\hline Activity score & & & \multirow{2}{*}{\multicolumn{2}{|c|}{$59 \cdot 4$}} & \multirow{2}{*}{\multicolumn{2}{|c|}{$58 \cdot 3$}} & 0.324 \\
\hline Mean & \multicolumn{2}{|c|}{59.5} & & & & & \\
\hline SD & \multicolumn{2}{|c|}{$16 \cdot 2$} & \multicolumn{2}{|c|}{$16 \cdot 3$} & \multicolumn{2}{|c|}{$16 \cdot 5$} & \\
\hline
\end{tabular}

* $P$ for trend when infant feeding is used as independent predictor and adult characteristics as dependent variables in univariate regression models. 
Table 4. Multivariate-adjusted prudent diet scores according to sex and early-life characteristics (Number of subjects, $\beta$ coefficients and $95 \%$ confidence intervals)

\begin{tabular}{|c|c|c|c|c|}
\hline & $n$ & $\beta$ & $95 \% \mathrm{Cl}$ & $P^{*}$ \\
\hline \multicolumn{5}{|l|}{ Sex } \\
\hline Male & 1677 & Baseline & - & \\
\hline Female & 1540 & 1.27 & $1.14,1.41$ & $<0.001$ \\
\hline \multicolumn{5}{|l|}{ Birth weight $(\mathrm{kg})$} \\
\hline$<3.18$ & 1200 & Baseline & - & \\
\hline $3.18-3.63$ & 1155 & 0.02 & $-0.14,0.17$ & \\
\hline$>3.63$ & 862 & -0.01 & $-0.18,0.16$ & 0.276 \\
\hline \multicolumn{5}{|c|}{ Type of milk feeding in infancy } \\
\hline Breast only & 1937 & Baseline & - & \\
\hline Breast + bottle & 984 & -0.16 & $-0.31,-0.02$ & \\
\hline Bottle only & 296 & -0.22 & $-0.45,0.02$ & 0.009 \\
\hline \multicolumn{5}{|l|}{ Weight gain in first year (SD) } \\
\hline$<-0.38$ (bottom) & 1074 & Baseline & - & \\
\hline-0.37 to 0.43 (middle) & 1079 & 0.20 & $0.04,0.36$ & \\
\hline$>0.43$ (top) & 1064 & 0.36 & $0.20,0.53$ & $<0.001$ \\
\hline
\end{tabular}

* $P$ for trend from the mutually adjusted model using continuous variables.

be consistent with experimental data from recent studies. For example, infants fed bitter-tasting protein hydrolysate formula milks exhibit a greater preference for foods with the same sensory attributes in later childhood ${ }^{(26,27)}$. Breast-feeding exposes infants to volatile flavour compounds from the maternal diet. In comparison with infants who are formula-fed, these exposures are much more variable, which is likely to have a significant impact on flavour learning in infancy ${ }^{(11)}$. Although there is some recent experimental evidence that later acceptance of foods is greater among children who were breastfed $^{(11,28)}$, this is difficult to assess, as the choice to breastfeed is also associated with differences in maternal education and diet ${ }^{(29)}$, and with differences in infant feeding practices $^{(30,31)}$. In the present study, this was not the case, as the type of milk feeding in infancy was not associated with differences in social class or birth order - both factors that are known to be associated with differences in childhood diet ${ }^{(14)}$. Another possibility is that the observed differences in adult food choice according to milk-feeding type resulted from differences in salt consumption in infancy as the relatively higher $\mathrm{Na}$ content of cows' milk, and early breast milk substitutes based on cows' milk ${ }^{(32)}$, would have led to greater intakes in the infants who were bottle-fed. In animal studies, early exposure to salt enhances adult intake of sweet and salty compounds ${ }^{(33)}$. In this study, many of the foods that characterised the diets of the men and women with low prudent diet scores are high in salt (e.g. chips and processed meat) and sugar (e.g. added sugar, cakes and biscuits). However, when the consumption of individual foods in adult life was considered, there was little evidence of more marked associations between consumption of salty and sugary foods and milk-feeding type.

The mechanisms that underlie the association between infant growth and adult dietary choices may include effects on early cognitive development. Brain growth is greatest in late gestation and in the first year of $\operatorname{life}^{(34)}$, and slow growth in infancy predicts poor cognitive performance in later life and lower educational attainment ${ }^{(35,36)}$. Batty et $a l .{ }^{(37)}$ have shown that mental ability assessed in childhood is predictive of later food choices, such that children with higher test scores at age 10 years have a greater consumption of fruit, vegetables and wholemeal bread and lower consumption of chips and white bread at the age of 30 years. The skills indicated by the cognitive tests, such as the ability to comprehend and reason, may affect the understanding of health messages and are therefore important for lifelong management of health behaviours. A recent review concluded that rapid infant growth does not lead to greater cognitive ability $^{(38)}$. However, most of the studies included were of children born in recent decades. In this historical cohort, where the majority of children were breastfed, the significance of greater infant growth may be different. The observed association between greater weight gain and adult diet was robust, and was not changed by adjustment for a range of other factors. While the data are therefore consistent with the possibility that greater weight gain in infancy was indicative of beneficial

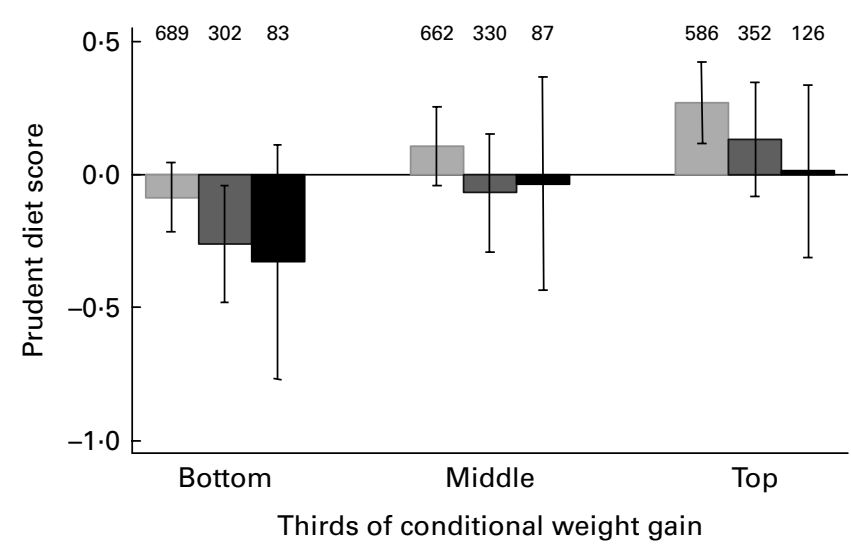

Fig. 1. Mean $(+95 \% \mathrm{Cl})$ prudent diet scores (adjusted for sex) by thirds of weight gain in first year and type of milk feeding (breast only $(\square)$; breast + bottle $(\square)$; bottle only $(\square)$ ). Average weight gain (adjusted for birth weight) was 5.53 (SD 0.50 ) $\mathrm{kg}$ for infants in bottom third, 6.54 (SD 0.31) kg in middle third and 7.63 (SD 0.65 ) kg in top third of the distribution. Number of participants in each of the nine groups is indicated above the bar. Associations between weight gain and type of milk feeding and prudent diet score are independent ( $P=0.009$ type of milk feeding; $P<0.001$ weight gain in first year). The $P$ values were obtained from multiple linear regression models. 
Table 5. Weekly adult consumption of selected foods according to type of infant feeding (Medians and interquartile ranges (IQR))

\begin{tabular}{|c|c|c|c|c|c|c|c|}
\hline & \multicolumn{2}{|c|}{ Breast } & \multicolumn{2}{|c|}{ Breast + bottle } & \multicolumn{2}{|c|}{ Bottle } & \multirow[b]{2}{*}{$P^{*}$} \\
\hline & Median & IQR & Median & IQR & Median & IQR & \\
\hline$n$ & \multicolumn{2}{|c|}{1937} & \multicolumn{2}{|c|}{984} & \multicolumn{2}{|c|}{296} & \\
\hline Salad vegetables (portions) $\dagger$ & $6 \cdot 5$ & $3.5-9.9$ & $6 \cdot 0$ & $3.5-9.7$ & $6 \cdot 0$ & $3.5-9.5$ & 0.177 \\
\hline Apples, bananas and other fruit (portions) & $10 \cdot 6$ & $6 \cdot 4-16 \cdot 0$ & $10 \cdot 5$ & $6 \cdot 0-16 \cdot 0$ & $9 \cdot 9$ & $5 \cdot 3-15 \cdot 5$ & $0 \cdot 186$ \\
\hline Oily fish (portions) & 0.7 & $0.5-1.5$ & 0.7 & $0.5-1 \cdot 2$ & $0 \cdot 7$ & $0.5-1 \cdot 2$ & 0.449 \\
\hline Brown and wholemeal bread (slices) & $2 \cdot 8$ & $0.0-8 \cdot 8$ & 1.5 & $0.0-8.8$ & $2 \cdot 8$ & $0.0-8 \cdot 8$ & 0.795 \\
\hline White bread (slices) & 3.5 & $0.5-8.8$ & $8 \cdot 8$ & $1.5-8 \cdot 8$ & $8 \cdot 8$ & $1.5-8.8$ & 0.169 \\
\hline Added sugar (teaspoons) & 0.0 & $0.0-21 \cdot 0$ & 0.0 & $0.0-21 \cdot 0$ & $3 \cdot 5$ & $0.0-28 \cdot 0$ & 0.025 \\
\hline Full-fat spread (portions) & 3.5 & $0.0-8 \cdot 8$ & 3.5 & $0.0-8 \cdot 8$ & 3.0 & $0.0-8 \cdot 8$ & 0.762 \\
\hline Processed meat (portions) $\ddagger$ & 3.5 & $2.0-5.5$ & 3.7 & $2 \cdot 4-5 \cdot 7$ & $3 \cdot 7$ & $2 \cdot 2-5.5$ & 0.019 \\
\hline Chips and roast potatoes (number of potatoes) & 1.5 & $0.8-2 \cdot 0$ & 1.5 & $0.8-2 \cdot 0$ & 1.5 & $0 \cdot 8-2 \cdot 0$ & 0.800 \\
\hline
\end{tabular}

${ }^{*} P$ for trend (using Spearman rank correlation) across the milk-feeding groups.

$\dagger$ Includes lettuce, tomatoes, coleslaw.

$\ddagger$ Includes bacon, sausages, meat pies.

effects on brain growth and later cognitive function, there may be other explanations, as such effects would also be expected to lead to differences in the other health behaviours. In the present study, there was no evidence of this.

A strength of this study is that a large population of older men and women were studied, for whom there was detailed contemporary information about infant feeding and growth. Although these data were not intended for future analyses, the categorisation of milk type is likely to indicate marked differences in exposure to breast milk, since feeding guidance in the 1930s recommended slow introduction of solid foods from around 8-9 months of age ${ }^{(24,39)}$. The high prevalence of breast-feeding in this cohort is consistent with other studies carried out in the $1930 \mathrm{~s}^{(15)}$. Confidence in the feeding data is borne out by the observed dose effects in the association between milk type and weight gain in the first year, with greater weight gains in the infants who were bottle-fed (Table 2). This is consistent with known differences in the patterns of growth of breastfed and formula-fed infants ${ }^{(40)}$. A weakness of the analyses is that there was no information on the type of milk substitutes fed to the men and women or on the duration of milk feeding in infancy, although the bottle-feeds are likely to have included commercial dried infant milks, unmodified cows' milk and diluted condensed milk $^{(24)}$. There is also no information on the nature of the participants' weaning diets, which may have differed between breastfed and bottle-fed infants. However, these difficulties in assessing dietary exposures in infancy would be expected to cause misclassification and lead to attenuation of associations. It is therefore possible that the described association between adult diet and type of milk in infancy is underestimated.

In terms of the adult characteristics assessed, membership of this cohort was defined by area of birth, and there has been loss to follow-up. However, the participants' characteristics are comparable with those of the wider community ${ }^{(17)}$ and the findings should therefore have relevance beyond the cohort. Diet was assessed using an FFQ that was administered by trained research nurses ${ }^{(18)}$. Although there is concern that FFQ can be prone to measurement error, they have been shown to define patterns in a comparable way to other dietary assessment methods ${ }^{(41,42)}$, and the patterns are predictive of biomarkers and a range of adult health outcomes ${ }^{(20,43,44)}$. A limitation of the analyses is that the examined associations were with current diet, and it will therefore be important to address the stability of the dietary patterns of the participants

Table 6. Weekly adult consumption of selected foods according to thirds of infant weight gain

(Medians and interquartile ranges (IQR))

\begin{tabular}{|c|c|c|c|c|c|c|c|}
\hline & \multicolumn{2}{|c|}{ Bottom } & \multicolumn{2}{|c|}{ Middle } & \multicolumn{2}{|c|}{ Top } & \multirow[b]{2}{*}{$P^{*}$} \\
\hline & Median & IQR & Median & IQR & Median & IQR & \\
\hline$n$ & \multicolumn{2}{|c|}{1074} & \multicolumn{2}{|c|}{1079} & \multicolumn{2}{|c|}{1064} & \\
\hline Salad vegetables (portions) $†$ & $6 \cdot 2$ & $3 \cdot 5-9 \cdot 7$ & $6 \cdot 4$ & $3.2-9.5$ & $6 \cdot 5$ & $4 \cdot 0-10 \cdot 0$ & 0.043 \\
\hline Apples, bananas and other fruit (portions) & $10 \cdot 0$ & $5 \cdot 6-15 \cdot 5$ & $10 \cdot 5$ & $6 \cdot 2-16 \cdot 0$ & 11.0 & $6 \cdot 5-17 \cdot 0$ & 0.002 \\
\hline Oily fish (portions) & 0.7 & $0.5-1.2$ & 0.7 & $0.5-1.2$ & 1.0 & $0.5-1.5$ & $<0.001$ \\
\hline Brown and wholemeal bread (slices) & 1.5 & $0.0-8.8$ & $2 \cdot 8$ & $0.0-8.8$ & $2 \cdot 8$ & $0.0-8.8$ & 0.038 \\
\hline White bread (slices) & $8 \cdot 8$ & $1.5-8.8$ & $8 \cdot 8$ & $0.5-8.8$ & 3.5 & $0.5-8.8$ & 0.017 \\
\hline Added sugar (teaspoons) & 0.0 & $0.0-28 \cdot 0$ & 0.0 & $0.0-21 \cdot 0$ & 0.0 & $0.0-21.0$ & 0.006 \\
\hline Full-fat spread (portions) & 3.5 & $0.0-8 \cdot 8$ & 3.5 & $0.0-8.8$ & 3.5 & $0.0-8.8$ & 0.543 \\
\hline Processed meat (portions) $\ddagger$ & $3 \cdot 7$ & $2 \cdot 2-6 \cdot 0$ & 3.5 & $2 \cdot 2-5.5$ & 3.5 & $2 \cdot 1-5 \cdot 2$ & 0.017 \\
\hline Chips and roast potatoes (number of potatoes) & 1.5 & $1 \cdot 0-2 \cdot 0$ & 1.5 & $0.8-2.0$ & 1.4 & $0.7-2.0$ & $<0.001$ \\
\hline
\end{tabular}

${ }^{\star} P$ for trend (using Spearman rank correlation) across thirds of infant weight gain.

†Includes lettuce, tomatoes, coleslaw.

$\ddagger$ Includes bacon, sausages, meat pies. 
in an ongoing follow-up of the cohort. A further consideration is that although the analyses were adjusted for a number of factors, there may be other unmeasured influences on infant feeding practice and on adult dietary choice that were not assessed, and the possibility of residual confounding in these associations cannot be excluded.

While the data suggest that differences in milk feeding and infant growth can have lifelong effects on food choice, it may be difficult to determine the relevance of these historical data for today's children. For example, the current composition of infant formula is very different from that of the breast milk substitutes available in the 1930s. Another key difference is the age at introduction of solid foods, which in the past was much later in infancy, and weaning may have been more gradual than it is today. Milk was therefore a relatively greater part of the infant diet. However, although comparable variations in dietary exposures may no longer exist, the findings are important. First, they lend support to experimental findings, that early dietary exposures have long-term effects on taste preferences. Secondly, they suggest that such effects could make an impact on food choices throughout life. Although these data need to be replicated in other cohorts, they provide further support for current infant feeding guidance - to breastfeed, and to provide a varied weaning diet based on fruit, vegetables and home-prepared food. Appropriate infant feeding is important not only to support early growth and development, but may also be involved in establishing good food habits in later life.

\section{Acknowledgements}

The authors thank all the men and women who took part in the Hertfordshire Cohort Study (HCS), the HCS research staff, and Vanessa Cox who managed the data. This work was supported by the Medical Research Council, UK and the University of Southampton. The authors' contributions to the study were as follows: S. R. was responsible for the collection and analysis of dietary data, and wrote the first draft of the paper. G. N. performed data analysis; D. B., H. S., A. A. S., E. D., S. S. and C. C. were responsible for the design and supervision of the HCS. All authors contributed to the interpretation of the analyses and the writing of the manuscript. None of the authors declared a conflict of interest.

\section{References}

1. Barker DJP (2004) The developmental origins of adult disease. J Am Coll Nutr 23, 588S-595S.

2. Martin RM, Gunnell D \& Davey Smith GD (2005) Breastfeeding in infancy and blood pressure in later life: systematic review and meta-analysis. Am J Epidemiol 161, 15-26.

3. Owen CG, Whincup PH, Kaye SJ, et al. (2008) Does initial breastfeeding lead to lower blood cholesterol in adult life? A quantitative review of the evidence. Am J Clin Nutr $\mathbf{8 8}$, 305-314.

4. Martin RM \& Davey Smith G (2009) Does having been breastfed in infancy influence lipid profile in later life?: a review of the literature. Adv Exp Med Biol 646, 41-50.
5. Harder T, Bergmann R, Kallischnigg G, et al. (2005) Duration of breastfeeding and risk of overweight: a meta-analysis. $\mathrm{Am}$ $J$ Epidemiol 162, 397-403.

6. Owen CG, Martin RM, Whincup PH, et al. (2005) Effect of infant feeding on the risk of obesity across the life course: a quantitative review of published evidence. Pediatrics 115, 1367-1377.

7. Owen CG, Martin RM, Whincup PH, et al. (2006) Does breastfeeding influence risk of type 2 diabetes in later life? A quantitative analysis of published evidence. Am J Clin Nutr 84, 1043-1054.

8. Singhal A \& Lanigan J (2007) Breastfeeding, early growth and later obesity. Obes Rev 8, 51-54.

9. Li R, Fein SB \& Grummer-Strawn LM (2010) Do infants fed from bottles lack self-regulation of milk intake compared with directly breastfed infants? Pediatrics 125, e1386-e1393.

10. Savino F \& Liguori S (2008) Update on breast milk hormones: leptin, ghrelin and adiponectin. Clin Nutr 27, 42-47.

11. Beauchamp GK \& Mennella JA (2009) Early flavor learning and its impact on later feeding behaviour. J Pediatr Gastroenterol Nutr 48, S25-S30.

12. Mennella JA, Griffin CE \& Beauchamp GK (2004) Flavor programming during infancy. Pediatrics 113, 840-845.

13. Martin RM, Goodall SH, Gunnell D, et al. (2007) Breast feeding in infancy and social mobility: 60-year follow-up of the Boyd Orr cohort. Arch Dis Child 92, 317-321.

14. Fisk CM, Crozier SR, Inskip HM, et al. (2011) Influences on the quality of young children's diets: the importance of maternal food choices. Br J Nutr 105, 287-296.

15. Spence JC (1938) The modern decline of breast-feeding. BMJ i, $729-732$.

16. Robinson M (1941) A comparison of breast-feeding in ten classes of the population. Arch Dis Child 16, 31-34.

17. Syddall HE, Sayer AA, Dennison EM, et al. (2005) Cohort profile: The Hertfordshire Cohort Study. Int J Epidemiol 34, $1234-1242$.

18. Robinson S, Syddall H, Jameson K, et al. (2009) Current patterns of diet in community-dwelling older men and women: results from the Hertfordshire Cohort Study. Age Ageing 38, 594-599.

19. Slattery ML, Boucher KM, Caan BJ, et al. (1998) Eating patterns and risk of colon cancer. Am J Epidemiol 148, 4-16.

20. Robinson S, Crozier SR, Borland SE, et al. (2004) Impact of educational attainment on the quality of young women's diets. Eur J Clin Nutr 58, 1174-1180.

21. Office of Population Censuses and Surveys (1990) Standard Occupational Classification. vol 1: Structure and Definition of Major, Minor and Unit Groups. London: HMSO.

22. Cole TJ (1995) Conditional reference charts to assess weight gain in British infants. Arch Dis Child 73, 8-16.

23. Sayer AA, Syddall HE, Dennison EM, et al. (2004) Birth weight, weight at 1 year of age, and body composition in older men: findings from the Hertfordshire Cohort Study. Am J Clin Nutr 80, 199-203.

24. Fall CH, Barker DJ, Osmond C, et al. (1992) Relation of infant feeding to adult serum cholesterol concentration and death from ischaemic heart disease. BMJ 304, 801-805.

25. StataCorp (2009) Stata Statistical Software: Release 11. College Station, TX: StataCorp.

26. Mennella JA, Forestell CA, Morgan LK, et al. (2009) Early milk feeding influences taste acceptance and liking during infancy. Am J Clin Nutr 90, 780S-788S.

27. Sausenthaler S, Koletzko S, Koletzko B, et al. (2010) Effect of hydrolysed formula feeding on taste preferences at 10 years. Data from the German infant nutritional intervention program plus study. Clin Nutr 29, 304-306. 
28. Hausner H, Nicklaus S, Issanchou S, et al. (2010) Breastfeeding facilitates acceptance of a novel dietary flavour compound. Clin Nutr 29, 141-148.

29. Fisk CM, Crozier SR, Inskip HM, et al. (2011) Breastfeeding and reported morbidity in infancy: findings from the Southampton Women's Survey. Matern Child Nutr 7, 61-70.

30. Noble S \& Emmett P (2006) Differences in weaning practice, food and nutrient intake between breast- and formula-fed 4-month-old infants in England. J Hum Nutr Diet 19, 303-313.

31. Robinson S, Marriott L, Poole J, et al. (2007) Dietary patterns in infancy: the importance of maternal and family influences on feeding practice. BrJ Nutr 98, 1029-1037.

32. Shaw JC, Jones A \& Gunther M (1973) Mineral content of brands of milk for infant feeding. BMJ 2, 12-15.

33. Smriga M, Kameishi M \& Torii K (2002) Brief exposure to $\mathrm{NaCl}$ during early postnatal development enhances adult intake of sweet and salty compounds. Neuroreport 13, 2565-2569.

34. Gale CR, O'Callaghan FJ, Bredow M, et al. (2006) The influence of head growth in fetal life, infancy and childhood on intelligence at the ages of 4 and 8 years. Pediatrics 118 1486-1492.

35. Räikkönen K, Forsén T, Henriksson M, et al. (2009) Growth trajectories and intellectual abilities in young adulthood: The Helsinki Birth Cohort study. Am J Epidemiol 170, 447-455.
36. Barker DJ, Eriksson JG, Forsén T, et al. (2005) Infant growth and income 50 years later. Arch Dis Child 90, 272-273.

37. Batty GD, Deary IJ, Schoon I, et al. (2007) Childhood mental ability in relation to food intake and physical activity in adulthood: the 1970 British cohort study. Pediatrics 119, e38-e45.

38. Beyerlein A, Ness AR, Streuling I, et al. (2010) Early rapid growth: no association with later cognitive functions in children born not small for gestational age. Am J Clin Nutr 92 , $585-593$.

39. Liddiard M (1936) The Mothercraft Manual, 9th ed. London: J\&A Churchill Ltd.

40. Dewey KG, Heinig MJ, Nommsen LA, et al. (1992) Growth of breastfed and formula-fed infants from 0 to 18 months: the DARLING study. Pediatrics 89, 1035-1041.

41. Hu FB, Rimm E, Smith-Warner SA, et al. (1999) Reproducibility and validity of dietary patterns assessed with a food frequency questionnaire. Am J Clin Nutr 69, 243-249.

42. Crozier SR, Inskip HM, Godfrey KM, et al. (2008) Dietary patterns in pregnant women: a comparison of food frequency questionnaires and $4 \mathrm{~d}$ prospective diaries. Br J Nutr 99, 869-875.

43. Fung TT, Rimm EB, Spiegelman D, et al. (2001) Association between dietary patterns and plasma biomarkers of obesity and cardiovascular disease risk. Am J Clin Nutr 73, 61-67.

44. Hu FB, Rimm EB, Stampfer MJ, et al. (2000) Prospective study of major dietary patterns and risk of coronary heart disease in men. Am J Clin Nutr 72, 912-921. 